\title{
Analgesic effect in humans of subanaesthetic isoflurane concentrations evaluated by experimentally induced pain
}

\author{
S. Petersen-Felix, L. Arendt-Nielsen, P. Bak, D. Roth, M. Fischer, P. Bjerring \\ AND A. M. ZBINDEN
}

\begin{abstract}
Summary
The analgesic effect of subanaesthetic concentrations of ether, trichloroethylene, methoxyflurane and halothane has been investigated previously using either clinical assessment or pain threshold measurements, but with conflicting results. The purpose of the present study was to evaluate the analgesic effect of isoflurane using experimental pain models. We studied 12 healthy volunteers at three randomly chosen subanaesthetic isoflurane concentrations: low $(0.10-0.14 \mathrm{vol} \%)$ middle $(0.16-0.20 \mathrm{vol} \%)$ and high (0.22-0.26 vol \%). We used thermal pain detection and pain tolerance thresholds to argon laser stimulation, pressure pain detection and pain tolerance thresholds, immersion of the hand in ice water, and the nociceptive reflex to single and repeated (temporal summation) electrical stimulations, as experimental models to assess analgesia. There were no significant changes in the response to heat, cold or mechanical pressure at any of the subanaesthetic concentrations of isoflurane used. The nociceptive reflex thresholds to single stimulations, but not the thresholds for repeated stimulations, were significantly increased in all three isoflurane groups compared with baseline values. The difference between the different isoflurane concentrations was not statistically significant. In experimental pain models, subanaesthetic isoflurane concentrations have little or no analgesic potency. (Br. J. Anaesth. 1995; 75: 55-60)
\end{abstract}

\section{Key words}

Anaesthetics volatile, isoflurane. Pain, experimental.

The potency of inhalation anaesthetics has been defined by the MAC concept [1]. The MAC concept does not distinguish between the different components of anaesthesia: hypnosis, analgesia and neuromuscular block.

The analgesic effect at subanaesthetic concentrations of the "older" inhalation anaesthetics (ether, trichloroethylene, methoxyflurane and halothane) has been investigated using either clinical assessment or pain threshold measurements [2-5], but with conflicting results. The purpose of the present study was to evaluate the analgesic effects of isoflurane on different pain modalities, using experimental models.

\section{Subjects and methods}

We studied 12 healthy volunteers (eight male, mean age 26 (range 20-42) yr) who were not receiving any medication, did not have any allergies or a history of adverse reactions to anaesthesia, and for female volunteers, were not pregnant. Written informed consent was obtained, and the study was approved by the Ethics Committee of the Faculty of Medicine, University of Bern.

In order to minimise the risk of acid aspiration, volunteers received omeprazole (Artra) $40 \mathrm{mg}$ the evening before the study and were tested after a fasting period of at least $6 \mathrm{~h}$. During testing, the volunteers rested comfortably in a supine position. An i.v. infusion of $\mathrm{NaCl}$-glucose was given as a safety precaution, and $\mathrm{Sp}_{\mathrm{O}_{2}}$, ECG and non-invasive arterial pressure were monitored continuously during the experiment. Subanaesthetic concentrations of isoflurane were delivered via a face mask. A diagram of the breathing system is shown in figure 1 . Fresh gas (air) was delivered to the breathing system via two flowmeters, the gas from one flowmeter passed through an isoflurane vaporizer. The gas from both flowmeters then passed through a mixing chamber. The concentration of isofhrane in the gas leaving the mixing chamber was monitored with an Irina (Drägerwerk, Lübeck, Germany) gas monitor. The isoflurane mixture was then fed to a conventional CPAP system (Ambu, Denmark); the pressure in the system was monitored with an external manometer, and total fresh gas flow regulated to maintain a continuous positive pressure of 3-5 $\mathrm{cm} \mathrm{H}_{2} \mathrm{O}$ during the respiratory cycle. A CPAP system was chosen to avoid mixture of room air with inspired gas via small leaks between the skin and the face mask. The face mask was attached using conventional rubber straps for CPAP masks. Inspiratory and expiratory gases were sampled close to the nostrils via a plastic tube fitted through a hole

Steen Petersen-Felix ${ }^{\star}, \mathrm{MD}$, DeEA, DANiel Roth, Michael FISCHER, MD, AlEX M. ZBINDEN, MD, PHD, Department of Anaesthesiology and Intensive Care, University Hospital of Bern, Switzerland. LARS ARENDT-NIELSEN, PHD, PETER BAK, MSCEE, Center for Sensory-Motor Interaction, Laboratory for Experimental Pain Research, University of Aalborg, Denmark. PETER BJERRING, MD, PHD, Department of Dermatology, University Hospital of Aarhus, Denmark. Accepted for publication: February 22, 1995.

*Address for correspondence: Institut für Anästhesie und Intensivbehandlung, Inselspital, CH-3010 Bern, Switzerland. 


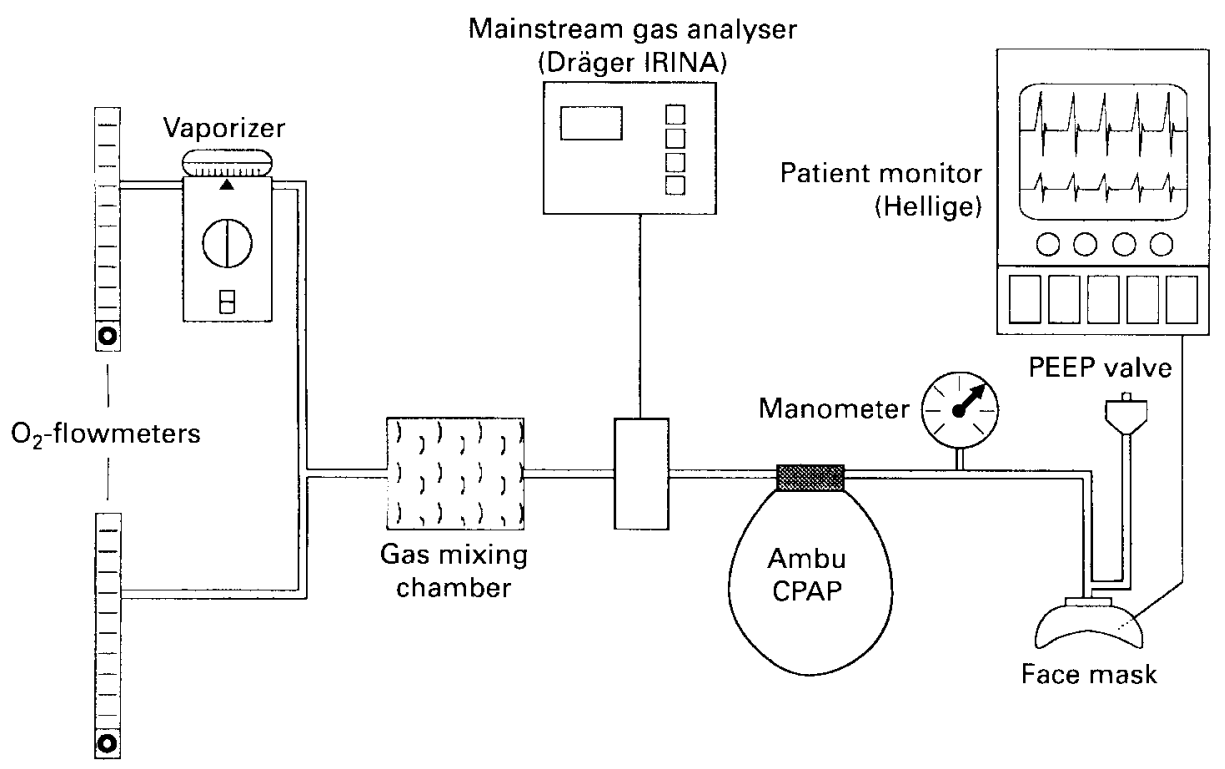

Figure 1 Diagram of the breathing system for subanaesthetic concentrations.

drilled in the mask and analysed with the anaesthetic gas module of a Hellige SMU 611 (PPG Hellige GMBH, Freiburg in B, Germany). The accuracy of the Hellige monitor for the subanaesthetic concentrations has been verified in our laboratory and referenced to a gas chromatograph. The gas monitors were calibrated every day according to the specifications of the manufacturer.

The following tests were performed in random order in each test series.

\section{Argon laser pain detection and pain tolerance thresholds}

The output from an argon laser (Spectra Physics 168) was transmitted via a single $0.2-\mathrm{mm}$ quartz fibre. The distance to the skin was adjusted to obtain a laser beam diameter of $1 \mathrm{~cm}$ on the skin. The output was adjusted to $2 \mathrm{~W}$ (controlled with an external power meter). A continuous stimulus was applied to the volar side of the forearm and a counter was begun at the start of the laser stimulation. The time until the volunteer started to feel pain was defined as pain detection, and the time when he wanted the stimulation to stop as the pain tolerance threshold. If the tolerance threshold was not reached within $30 \mathrm{~s}$ the stimulation was discontinued (in order to avoid skin damage), and the pain tolerance threshold was defined as $30 \mathrm{~s}$ in such cases. Repeated testing in the same area was avoided.

\section{Ice water test}

A 2-min ice water test was used $[6,7]$. The right hand was immersed in ice-saturated water $\left(1.5 \pm 1.0^{\circ} \mathrm{C}\right)$. If the pain was considered intolerable before $2 \mathrm{~min}$ had elapsed, the volunteer could withdraw the hand and the elapsed time was noted. Pain intensity was rated continuously with an electronic visual analogue scale (VAS) coupled to a pen recorder. The area under the pain intensity-time curve was determined. If the hand was withdrawn before the end of the $2 \mathrm{~min}$, pain intensity was considered to be maximal until the end of the period.

\section{Mechanical pressure pain detection and pain tolerance thresholds}

Pressure pain detection and pain tolerance thresholds were determined on the centre of the pulp of the second (pain detection) and third (tolerance) fingers of the right hand with an electronic pressure algometer (Somedic AB, Stockholm, Sweden) [8-10]. A probe with a surface area of $0.28 \mathrm{~cm}^{2}$ was used and the rate of pressure increase was $30 \mathrm{kPa} \mathrm{s}^{-1}$. Pain detection was defined as the point when pressure turned into pain, and pain tolerance as the point when the volunteer did not wish the pressure to be increased further. For the determination of both thresholds, the mean of two consecutive measurements was used.

\section{Nociceptive reflex to single stimuli}

The sural nerve was stimulated with a single $25-\mathrm{ms}$ stimulus (in reality a train of five 1-ms square-wave impulses, but this is perceived as a single stimulus) behind the right lateral malleolus via surface electrodes filled with electrode gel (inter-electrode distance approximately $3 \mathrm{~cm}$ ). Electromyographic reflex responses were recorded with surface electrodes placed midway over the biceps femoris and rectus femoris. From the trial testing the approximate current intensity threshold which could just elicit a reflex was determined. The current was increased from $5 \mathrm{~mA}$ below this level in steps of 1-2 mA until a reflex of the ipsilateral femur with an amplitude exceeding $20 \mu \mathrm{V}$ for at least $10 \mathrm{~ms}$ was recorded three times at the same current intensity. This was defined as the nociceptive reflex threshold. If no reflex could be recorded at a maximal current of $80 \mathrm{~mA}$, this was defined as the threshold. After 
each threshold determination the volunteer rated the subjective pain perceived at the threshold stimulation on a visual analogue scale.

\section{Nociceptive reflex to repeated stimuli}

The sural nerve was stimulated as described above, but the single stimulus was repeated five times with a frequency of $2 \mathrm{~Hz}$ [11]. Current intensity was increased from $2 \mathrm{~mA}$ in steps of $1-2 \mathrm{~mA}$ until summation was observed in the reflex response. Summation was defined as an increase in amplitude of the last one or two reflexes, for example the amplitude of the reflex elicited by the first three impulses was below, but the amplitudes of the fourth, fifth, or both, impulses were above $20 \mu \mathrm{V}$ for at least $10 \mathrm{~ms}$.

\section{Reaction time}

A tone was delivered from a computer with randomized intervals of 3-8 s, and a timer was started simultaneously. The volunteer was instructed to press a button as fast as possible after the tone. The reaction time was defined as the time from the tone until the volunteer pressed the button. The mean of three consecutive measurements was used.

The pain tests were explained to the volunteer, and a trial test of all techniques was performed in order to familiarize the volunteer with the procedure. The mask was then fitted, and the volunteer breathed air for $5 \mathrm{~min}$ or until he felt comfortable, and there were no leaks from the mask. A baseline test series of the tests described above was then performed. Thereafter isoflurane was introduced slowly into the breathing system and adjusted to the chosen endtidal concentration. Isoflurane concentrations from $0.10-0.26$ vol \% were divided into low $(0.10,0.12$, 0.14 vol \%), middle $(0.16,0.18,0.20 \mathrm{vol} \%)$ and high $(0.22,0.24,0.26 \mathrm{vol} \%)$ groups. We did not use concentrations higher than $0.26 \mathrm{vol} \%$ (approximately 0.2 MAC isoflurane), as volunteers at higher concentrations tend to be too sedated to co-operate [12]. All volunteers received one concentration from each group in random order by drawing lots. The concentration used from each group was also chosen randomly by drawing lots. After 15 min equilibration at a constant end-tidal concentration, a test series was performed. This procedure was repeated with the two other isoflurane concentrations. The isoflurane concentration delivered was known only to the anaesthetist delivering the "anaesthesia", but unknown to the volunteer and the two other persons performing the test procedures. The blinding was not complete, as a difference in sedation from low to high concentrations could be observed. After testing had been performed at all three isoflurane concentrations, isoflurane was discontinued. A final postgas test series was then performed after the volunteer had breathed air via the mask for $30 \mathrm{~min}$.

Statistical analysis was performed independently for each pain test with the software package SigmaStat ver 1.01 (Jandel Scientific GmbH,
Erkrath, Germany). The numerical values for each measurement were transformed to percentage of baseline measurements. Results for isoflurane concentrations $0.10-0.14 \mathrm{vol} \%$ were pooled in a low concentration group, $0.16-0.20 \mathrm{vol} \%$ in a middle and $0.22-0.26 \mathrm{vol} \%$ in a high concentration group. Median values and quartiles were calculated for each group and for the final post-gas measurements. For each pain test, the low, middle and high concentration groups were compared with baseline using Friedman's test for repeated measures analysis of variance on ranks, and the Student-Newman-Keuls test for multiple comparison. Wilcoxon's signed rank test was used to test for baseline drift by comparing the post-gas values with baseline values.

\section{Results}

There were no significant changes in the response to heat, cold, mechanical pressure or the threshold for summation of the nociceptive reflex to repeated electrical stimulations at any of the subanaesthetic isoflurane concentrations used (table 1). The threshold for the nociceptive reflex to single electrical stimulation was increased significantly in all three isoflurane concentration groups compared with baseline values. The median increase was $125.0 \%$ in the low, $135.0 \%$ in the middle and $156.9 \%$ in the high concentration group, but the difference between the various isoflurane concentrations was not statistically significant.

The perceived pain at the threshold for the nociceptive reflex to single electrical stimulation remained constant. Thirty minutes after isoflurane had been discontinued, the pain detection threshold to electrical stimulation was $127.8 \%$. This was significantly different from baseline, but also significantly different from the high concentration group. Reaction time did not change in the low concentration group, but was significantly changed in the middle and high concentration groups, and it had returned to baseline values $30 \mathrm{~min}$ after discontinuation of isoflurane.

\section{Discussion}

We have found that subanaesthetic isoflurane concentrations did not change the responses to pain induced experimentally with heat, cold, mechanical pressure or the threshold for the summation of the nociceptive reflex to repeated electrical stimulations. However, there was a small increase in the threshold to single electrical stimulations. This indicates that isoflurane in subanaesthetic concentrations had no, or minimal, analgesic effects and so would not be of clinical relevance.

Dundee, Nicholl and Black [13] studied the effects of $1-2 \%$ ether, 25,33 and $50 \%$ nitrous oxide, $5 \%$ cyclopropane, 0.35 and $0.5 \%$ trichloroethylene, $0.5 \%$ halothane and the halothane-ether azeotrope mixture $(1.0$ and $1.5 \%)$ on tibia pain thresholds. They found that the pain threshold increased for the first four agents, but surprisingly not for halothane or for the halothane-ether azeotrope. Halothane seemed to produce hyperalgesia, as the pressure pain 
Table 1 Results from the experimental pain tests (median (25-75 percentiles)). Values are expressed as percentage change from baseline. ${ }^{\star} P<0.05$ compared with baseline, ns $=$ not significant compared with baseline

\begin{tabular}{|c|c|c|c|c|}
\hline \multirow[b]{2}{*}{ Pain test } & \multicolumn{3}{|l|}{ Isoflurane $(\%)$} & \multirow[b]{2}{*}{ Post-gas } \\
\hline & $0.10-0.14$ & $0.16-0.20$ & $0.22-0.26$ & \\
\hline $\begin{array}{l}\text { Laser heat } \\
\text { pain threshold }\end{array}$ & $\begin{array}{l}\mathrm{ns} \\
100.4(87.6-129.2)\end{array}$ & $\begin{array}{l}\text { ns } \\
115.8(86.3-135.5)\end{array}$ & $\begin{array}{l}\text { ns } \\
124.6(77.3-159.7)\end{array}$ & $\begin{array}{l}\text { ns } \\
102.2(71.0-134.5)\end{array}$ \\
\hline $\begin{array}{l}\text { Laser heat } \\
\text { pain tolerance }\end{array}$ & $\begin{array}{l}\text { ns } \\
95.5(83.4-102.2)\end{array}$ & $\begin{array}{l}\text { ns } \\
96.0(74.1-123.7)\end{array}$ & $\begin{array}{l}\text { ns } \\
126.8(100-149.0)\end{array}$ & $\begin{array}{l}\text { ns } \\
94.3(83.7-113.0)\end{array}$ \\
\hline $\begin{array}{l}\text { Ice water } \\
\text { pain tolerance }\end{array}$ & $\begin{array}{l}\text { ns } \\
83.1(81.1-97.2)\end{array}$ & ns $94.1(85.9-102.1)$ & ns $96.3(91.4-105.5)$ & $\begin{array}{l}\text { ns } \\
102.3(97.5-110.4)\end{array}$ \\
\hline $\begin{array}{l}\text { Mechanical pressure } \\
\text { pain threshold }\end{array}$ & $\begin{array}{l}\text { ns } \\
103.1(94.1-112.7)\end{array}$ & $\begin{array}{l}\text { ns } \\
102.4(96.2-115.7)\end{array}$ & $\begin{array}{l}\text { ns } \\
116.7(103.5-141.7)\end{array}$ & $\begin{array}{l}\text { ns } \\
99.7(93.2-121.2)\end{array}$ \\
\hline $\begin{array}{l}\text { Mechanical pressure } \\
\text { pain tolerance }\end{array}$ & $\begin{array}{l}\text { ns } \\
88.7(82.1-94.5)\end{array}$ & $\begin{array}{l}\text { ns } \\
85.5(77.8-93.8)\end{array}$ & $\begin{array}{l}\mathrm{ns} \\
85.1(72.8-106.4)\end{array}$ & $\begin{array}{l}\text { ns } \\
91.2(83.5-102.9)\end{array}$ \\
\hline $\begin{array}{l}\text { Nociceptive reflex threshold } \\
\text { single stimulations }\end{array}$ & ${ }^{\star} 125.0(119.9-152.8)$ & ${ }^{\star} 135.0(127.9-172.2)$ & ${ }^{\star} 156.9(125.0-170.8)$ & * $127.8(100.0-133.3)$ \\
\hline $\begin{array}{l}\text { Nociceptive reflex } \\
\text { VAS pain score }\end{array}$ & $\begin{array}{l}\text { ns } \\
100.5(91.2-121.6)\end{array}$ & ns $87.5(81.2-101.4)$ & $\begin{array}{l}\mathrm{ns} \\
98.8(82.5-118.4)\end{array}$ & $\begin{array}{l}\text { ns } \\
100.7(91.3-114.3)\end{array}$ \\
\hline $\begin{array}{l}\text { Nociceptive reflex threshold } \\
\text { repeated stimulations }\end{array}$ & $\begin{array}{l}\text { ns } \\
100.0(89.2-115.0)\end{array}$ & $\begin{array}{l}\text { ns } \\
90.9(70.7-113.2)\end{array}$ & $\begin{array}{l}\text { ns } \\
100.0(89.4-111.5)\end{array}$ & 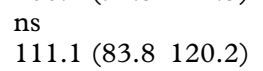 \\
\hline Reaction time & $\begin{array}{l}\mathrm{ns} \\
102.3(99.2-110.8)\end{array}$ & * $121.5(102.1-161.5)$ & ^ $153.4(123.3-183.4)$ & $\begin{array}{l}\text { ns } \\
107.2(79.8-111.6)\end{array}$ \\
\hline
\end{tabular}

thresholds decreased. Only the inspired concentrations were measured, and the agents were inhaled for only 5-8 min, and therefore steady state conditions were not achieved. Using the same analgesimetry method, Dundee and Love [14] found no increase in pain thresholds when subanaesthetic concentrations of methoxyflurane were inhaled. Later studies found that halothane increased pain thresholds to heat [15] and pressure $[5,15]$, and that methoxyflurane increased pain thresholds to pressure $[4,5]$. In these older studies, simple pain models were used, and most measurements were performed under nonsteady state conditions. Recently, Tomi and colleagues [16] found that 0.2 MAC of halothane, enflurane, isoflurane and sevoflurane produced no change in the heat pain threshold. The present study combined subjective ratings with objective measurements of several pain modalities (heat, cold, pressure and electrical stimulation) under controlled steady state conditions.

It is possible that the experimental pain models used in the present study were unable to detect a weak analgesic effect of subanaesthetic isoflurane concentrations. In an earlier study [17] we found that alfentanil $30 \mu \mathrm{g}$ i.m. significantly changed the reaction to laser heat pain tolerance, cold pain tolerance, mechanical pain tolerance and electrical stimulation, when similar methods were used as in the present study. Arendt-Nielsen, Øberg and Bjerring [18] used brief argon laser pulses covering a small area to determine the analgesic effect of alfentanil. The same method has also been used to show an analgesic effect of weak analgesics [19-21]. Ice water stimulation has been used to demonstrate an analgesic effect of morphine [7,22], but it failed to detect an analgesic effect of acetylsalicylic acid [22] and ibuprofen [7]. Ketoprofen [23] and acetylsalicylic acid [24] have both been shown to increase the threshold of the nociceptive reflex to single stimulations. Heat, pressure and electrical stimuli, but perhaps not the ice water test, should be able to detect weak analgesic effects.
Willer [25] found the threshold of the nociceptive reflex to single stimulations to correspond to the pain detection threshold. We found a significant increase in the threshold for the nociceptive reflex to single stimulations, but no increase in perceived pain, indicating that the close link between the threshold for the nociceptive reflex to single stimulations and the pain detection threshold remained during sedation with subanaesthetic isoflurane concentrations. Thirty minutes after discontinuation of isoflurane the threshold for the nociceptive reflex to single stimulations had not returned to baseline values. Willer and colleagues [23] have shown that the threshold increased by $17 \%$ after determinations every $5 \mathrm{~min}$ for $60 \mathrm{~min}$, possibly because repeated stimulation causes receptor fatigue. We performed 5-6 determinations in the course of $3 \mathrm{~h}$ to avoid fatigue, but perhaps a small residual isoflurane concentration was still present after 30 min washout and this also contributed.

The threshold for the nociceptive reflex to single stimulation may be considered the most sensitive of the experimental pain tests used in the present study, but in a comparative study with propofol and alfentanil, a greater increase in the reflex threshold to single stimulations was found with propofol than with alfentanil [Petersen-Felix and co-workers, unpublished results], indicating that the increase in threshold could result from sedation.

Several studies have shown that fentanyl $[26,27]$ and alfentanil $[28,29]$ can reduce the haemodynamic response to intubation, and that attenuation of the increase in arterial pressure was dose-dependent [26 29]. The effects of isoflurane on haemodynamic reactions to standardized pain stimuli, including intubation, have been studied by Zbinden, PetersenFelix and Thomson [30]. They showed that the increase in arterial pressure after a standardized pain stimulus could not be diminished by increasing the isoflurane concentration, even when concentrations exceeding 2 MAC were used. This indicates that isoflurane has no analgesic effects or that a weak 
analgesic effect reaches a maximum at concentrations lower than those used in the study of Zbinden, Petersen-Felix and Thomson.

In clinical investigations in obstetrics [31,32], methoxyflurane was found to produce good analgesia in concentrations producing drowsiness but with patient co-operation being maintained. Later clinical studies with subanaesthetic concentrations of enflurane and isoflurane have shown that they have analgesic effects in labour [33-37]. Clinical studies rely on subjective evaluation of pain. It may be difficult to distinguish between sedative and analgesic effects, and steady state conditions with a constant end-tidal concentration were not achieved, so the effective concentration remains unknown. Furthermore, inhalation anaesthetics have a relaxant effect on uterine muscle $[38,39]$, so that the analgesic effect could be caused by reduction in intensity of the contractions. Isoflurane has been used for sedation in intensive care [40], but the present study indicates that analgesics are necessary as a supplement to isoflurane.

\section{References}

1. Eger EI, Saidman LJ, Brandstater B. Minimum alveolar anesthetic concentration: A standard of anesthetic potency. Anesthesiology 1965; 26: 756-763.

2. Artusio JF. Ether analgesia during major surgery. Fournal of the American Medical Association 1955; 157: 33-36.

3. Major V, Rosen M, Mushin WW. Methoxyflurane as an obstetric analgesic: a comparison with trichloroethylene. British Medical fournal 1966; 2: 1554-1561.

4. Oyama T, Maeda A, Kimura H. Effect of methoxyflurane analgesia by "Analgizer" on pain thresholds, blood levels, electroencephalogram, and blood gas. Anesthesia and Analgesia 1971 ; 50: 43-46.

5. Siker ES, Wolfson B, Ciccarelli HE, Telan RA. Effect of subanesthetic concentrations of halothane and methoxyflurane on pain threshold in conscious volunteers. Anesthesiology 1967; 28: 337-342.

6. Sindrup SH, Poulsen L, Brøsen K, Arendt-Nielsen L, Gram LF. Are poor metabolisers of sparteine/debrisoquine less pain tolerant than extensive metabolisers? Pain 1993; 53: 335-349.

7. Jones SF, McQuay HJ, Moore RA, Hand CW. Morphine and ibuprofen compared using the cold pressor test. Pain 1988; 34: $117-122$.

8. Brennum B, Kjeldsen M, Jensen K, Jensen TS. Measurement of human pressure-pain thresholds on fingers and toes. Pain 1989; 38: 211-217.

9. Dahl JB, Rosenberg J, Molke Jensen F, Kehlet H. Pressure pain thresholds in volunteers and herniorrhaphy patients. Acta Anaesthesiologica Scandinavica 1990; 34: 673-676.

10. Brennum J, Arendt-Nielsen L, Secher NH, Jensen TS, Bjerring P. Quantitative sensory examination in human epidural anaesthesia and analgesia: effects of lidocaine. Pain 1992; 51: 27-34.

11. Arendt-Nielsen L, Brennum J, Sindrup S, Bak P. Electrophysiological and psychophysical quantification of central temporal summation of the human nociceptive system. European Fournal of Applied Physiology 1994; 68: 266-273.

12. Newton DBF, Thornton C, Konieczko K, Frith CD, Doré CJ, Webster NR, Luff NP. Levels of consciousness in volunteers breathing sub-MAC concentrations of isoflurane. British fournal of Anaesthesia 1990; 65: 609-615.

13. Dundee JW, Nicholl RM, Black GW. Alterations in response to somatic pain associated with anaesthesia X: Further studies with inhalational agents. British fournal of Anaesthesia 1962; 34: 158-160.
14. Dundee JW, Love WJ. Alterations in response to somatic pain associated with anaesthesia XIV: Effects of subnarcotic concentrations of methoxyflurane. British fournal of $\mathrm{An}$ aesthesia 1963; 35: 301-304.

15. Robson JG, Davenport HT, Sugiyama R. Differentiation of two types of pain by anesthetics. Anesthesiology 1965; 26: 31-36.

16. Tomi K, Mashimo T, Tashiro C, Yagi M, Pak M, Nishimura $S$, Nishimura M, Yoshiya I. Alterations in pain threshold and psychomotor response associated with subanaesthetic concentrations of inhalation anaesthetics in humans. British Fournal of Anaesthesia 1993; 70: 684-686.

17. Petersen-Felix S, Arendt-Nielsen L, Bak P, Bjerring P, Breivik H, Svensson P, Zbinden AM. Ondansetron does not inhibit the analgesic effect of alfentanil. British fournal of Anaesthesia 1994; 73: 326-330.

18. Arendt-Nielsen L, Øberg B, Bjerring P. Analgesic efficacy of i.m. alfentanil. British Fournal of Anaesthesia 1990; 65: $164-168$

19. Nielsen JC, Bjerring P, Arendt-Nielsen L, Petterson KJ. A double-blind, placebo-controlled, cross-over comparison of the analgesic effect of ibuprofen $400 \mathrm{mg}$ and $800 \mathrm{mg}$ on laserinduced pain. British Fournal of Clinical Pharmacology 1990; 30: 711-715

20. Nielsen JC, Bjerring P, Arendt-Nielsen L, Petterson KJ. Analgesic efficacy of immediate and sustained release paracetamol and plasma concentrations of paracetamol. Double blind, placebo-controlled evaluation using painful laser stimulation. European fournal of Clinical Pharmacology 1992; 42: 261-264.

21. Sindrup SH, Brøsen K, Bjerring P, Arendt-Nielsen L, Larsen U, Angelo HR, Gram LF. Codeine increases pain thresholds to copper vapor laser stimuli in extensive but not poor metabolizers of spartine. Clinical Pharmacology and Therapeutics 1990; 48: 686-693.

22. Wolff BB, Kantor TG, Jarvik ME, Liska E. Response of experimental pain to analgesic drugs. I. Morphine, aspirin and placebo. Clinical Pharmacology and Therapeutics 1966; 7: 244-238.

23. Willer JC, De Broucker T, Bussel B, Roby-Brami A, Harrewyn JM. Central analgesic effect of ketoprofen in humans: electrophysiological evidence for a supraspinal mechanism in a double-blind cross-over study. Pain 1989; 38: $1-7$.

24. Willer JC, Bathien N. Pharmacological modulations on the nociceptive flexion reflex in man. Pain 1977; 3: 111-119.

25. Wilier JC. Comparative study of perceived pain and nociceptive flexion reflex in man. Pain 1977; 3: 69-80.

26. Kautto UM. Attenuation of the circulatory response to laryngoscopy and intubation by fentanyl. Acta Anaesthesiologica Scandinavica 1982; 26: 217-221.

27. Kay B, Healy TEJ, Bolder PM. Blocking the circulatory response to tracheal intubation. Anaesthesia 1985; 40 960-963.

28. Crawford DC, Fell D, Achola KJ, Smith G. Effects of alfentanil on the pressor and catecholamine response to tracheal intubation. British fournal of Anaesthesia 1987; 59. 707-712.

29. Scheinin B, Scheinin M, Vuorinen J, Lindgren L. Alfentanil obtunds the cardiovascular and sympathoadrenal response to suxamethonium-facilitated laryngoscopy and intubation. British fournal of Anaesthesia 1989; 62: 385-392.

30. Zbinden AM, Petersen-Felix S, Thomson DA. Anesthetic depth defined using multiple noxious stimuli during isoflurane/oxygen anesthesia. II. Hemodynamic responses. Anesthesiology 1994; 80: 261-267.

31. Romagnoli A, Korman D. Methoxyflurane in obstetrical anaesthesia and analgesia. Canadian Anaesthetists Society fournal 1962; 9: 414-418.

32. Bodley PO, Mirza V, Spears JR, Spilsbury RA. Obstetric analgesia with methoxyflurane. Anaesthesia 1966; 21: 457-463.

33. Abboud TK, Schnider SM, Wright RG, Rolbin SH, Craft JB, Henriksen EH, Johnson J, Jones MJ, Hughes SC, Levinson G. Enflurane analgesia in obstetrics. Anesthesia and Analgesia 1981; 60: 133-137.

34. McGuinness C, Rosen M. Enflurane as an analgesic in labour. Anaesthesia 1984; 39: 24-26. 
35. McLeod DD, Ramayya GP, Tunstall ME. Self-administered isoflurane in labour. A comparative study with entonox. Anaesthesia 1985; 40: 424-426.

36. Abboud TK, Gangolly J, Mosaad P, Crowell D. Isoflurane in obstetrics. Anesthesia and Analgesia 1989; 68: 388-391.

37. Wee MYK, Hasan MA, Thomas TA. Isoflurane in labour. Anaesthesia 1993; 48: 369-372.

38. Naftalin NJ, McKay DM, Phear WPG, Goldberg AH. The effects of halothane on pregnant and nonpregnant human myometrium, Anesthesiology 1977; 46: 15-19.

39. Munson ES, Embro WJ. Enflurane, isoflurane, and halothane and isolated human uterine muscle. Anesthesiology 1977; 46: 11-14.

40. Kong KL, Willats SM, Prys-Roberts C. Isoflurane compared with midazolam for sedation in the intensive care unit, British Medical fournal 1989; 298: 1277-1280. 